\title{
Competição entre Plantas de Arroz e biótipos de Capim-Arroz (Echinochloa spp.) RESISTENTE E SUSCETÍVEL AO QUINCLORAC
}

\author{
Competition Between Rice Plants and Echinochloa spp. Biotypes Resistant or Susceptible to \\ Quinclorac
}
GALON, L. ${ }^{2}$, CONCENÇO, G. ${ }^{3}$, FERREIRA, E.A. ${ }^{4}$, SILVA, A.F. ${ }^{5}$, FERREIRA, F.A. ${ }^{6}$, NOLDIN, J.A. ${ }^{7}$ e FREITAS, M.A.M. ${ }^{8}$

\begin{abstract}
RESUMO - Objetivou-se com este trabalho avaliar a competitividade interespecifica de biótipos de capim-arroz resistente (R) e suscetivel (S) ao herbicida quinclorac com a cultura do arroz irrigado. O experimento foi instalado em casa de vegetação e os tratamentos consistiram em manter uma planta de arroz cv. BRS Pelota no centro da unidade experimental, variando-se na periferia as densidades de capim-arroz em: 0, 1, 2, 3, 4 ou 5 plantas do biótipo R (ITJ-13) ou S (ITJ-17) oriundos da região de Itajaí-SC. O delineamento experimental utilizado foi o completamente casualizado, em esquema fatorial $2 \times 6 \mathrm{com}$ quatro repetições. Aos 40 dias após a emergência, foram avaliados as massas fresca e seca e o conteúdo de água de folhas, colmos e total da parte aérea do arroz e do capim-arroz. Houve efeito significativo dos tratamentos para todas as variáveis estudadas quando a cultura do arroz foi cultivada na presença de biótipos de capim-arroz R ou S. Esse efeito foi aditivo na proporção de 1 planta m². Entretanto, a capacidade competitiva dos biótipos de capim-arroz resistente e suscetivel ao quinclorac, com as plantas de arroz, apresentou comportamento similar quando se variou a densidade de plantas por área.
\end{abstract}

Palavras-chave: interferência, resistência, controle químico, recursos do ambiente.

ABSTRACT - This work aimed to evaluate the interspecific competitiveness of Echinochloa spp. biotypes resistant or susceptible to the herbicide quinclorac. The trial was installed under greenhouse conditions, with the biotypes resistant (ITJ-13) and susceptible (ITJ-17) to quinclorac under competition with the rice plants. The treatments consisted of maintaining one rice plant at the center of the experimental unit, surrounded by $0,1,2,3,4$ or 5 Echinochloa plants, according to the treatment. The trial was arranged in a completely randomized blocks design and factorial scheme $2 \times 6$, with four replications. Forty days after emergence, fresh dry weights and water content of the shoots were evaluated. There was a significant effect for all the variables when the rice was grown in the presence of R or $\mathbf{S}$. Echinochloa spp. This effect was additive in the proportion of one plant $m^{-2}$. However, the competitive capacity of $R$ and $S$ to quinclorac Echinochloa spp biotypes against the rice plants showed similar behavior when plant density per area varied.

Keywords: interference, resistance, chemical control, environmental resources.

\section{INTRODUÇÃO}

A cultura do arroz (Oryza sativa) é uma das mais importantes do mundo, sendo cultivada nos mais diversos ambientes em todos os continentes por apresentar facilidade de adaptação a condições edafoclimáticas distintas (Ruiz-Santella et al., 2003). No Brasil, encontra-se amplamente difundida em praticamente todos os Estados da Federação.

1 Recebido para publicação em 5.9.2008 e na forma revisada em 13.11.2009.

2 Eng-Agro ${ }^{-}$D.Sc., Professor da Faculdade da Amazônia - FAMA, Curso de Agronomia, Rua 743, número 2043, Bairro Cristo Rei, 76980-000 Vilhena-RO, <galoleandro@ig.com.br>; ${ }^{3}$ Eng-o-Agr $^{-}$, D.Sc. em Fitotecnia, International Agronomist, Valmont Industries, <gconcenco@yahoo.com.br>; ${ }^{4}$ Engo-Agro ${ }^{\circ}$, D.Sc., Pós Doutorado, Dep. de Fitotecnia, Universidade Federal de Viçosa - DFT/UFV, Bolsista do CNPq; ${ }^{5}$ Eng-Agro - , Doutorando, DFT/UFV, Bolsista do CNPq; ${ }^{6}$ Professor, DFT/UFV, Bolsista em Pesquisa do CNPq; ${ }^{7}$ Engô-Agrº ${ }^{\circ}$ Ph.D., Pesquisador da área de Plantas Daninhas da EPAGRI/EEI, Itajaí-SC e Prof. Colaborador do Programa de Pós-Graduação em Fitossanidade na Universidade Federal de Pelotas, <noldin@epagri.ret-se.br>; ${ }^{8}$ Aluno de graduação em Agronomia da UFV.

Planta Daninha, Viçosa-MG, v. 27, n. 4, p. 701-709, 2009 
No entanto, nos Estados do Sul, essa cultura ocupa grandes extensões de áreas cultivadas, e lá também se obtêm as maiores produtividades (IRGA, 2008). Contudo, sabe-se que o potencial de produtividade da cultura ainda pode ser melhorado; entre os muitos fatores que interferem no aumento da produtividade do cereal, destaca-se a competição com as plantas daninhas, cuja ausência de controle pode ocasionar perdas de produção de grãos superiores a $85 \%$ (Fleck et al., 2004).

Entre as espécies daninhas comuns nas lavouras orizicolas, destaca-se o capim-arroz (Echinochloa spp.). Esta apresenta muitas semelhanças morfofisiológicas com as plantas de arroz, além de vasta distribuição nas lavouras cultivadas e altos niveis de infestação. A principal forma de interferência que se estabelece entre capim-arroz e arroz irrigado é a competição pelos recursos luz e nutrientes, e isso constitui um dos principais fatores limitantes da produtividade nas lavouras de arroz irrigado do Rio Grande do Sul e de Santa Catarina (SOSBAI, 2005; Andres et al., 2007; Galon et al. 2007a,b; Concenço, et al. 2009).

O método de controle das plantas daninhas mais utilizado na lavoura arrozeira é o químico, pela praticidade e alta eficiência. Atualmente existem 17 herbicidas registrados, abrangendo nove mecanismos de ação, recomendados para o controle de capim-arroz (SOSBAI, 2005). Entretanto, o uso contínuo de herbicidas com o mesmo mecanismo de ação - quase sempre na ausência de rotação de culturas e de manejo integrado das plantas daninhas - tem favorecido o aparecimento de populações de capim-arroz com resistência a vários herbicidas (Ruiz-Santella et al., 2003); algumas inclusive com resistência múltipla (López-Martinez et al., 1997). No Brasil, biótipos de capim-arroz resistentes ao herbicida quinclorac estão amplamente distribuídos nos Estados de Santa Catarina e Rio Grande do Sul, onde se concentram cerca de $60 \%$ da produção nacional de arroz. Além disso, estudos preliminares indicam que os biótipos resistentes apresentam ampla distinção morfofisiológica entre si e que, provavelmente, a resistência se desenvolveu independentemente nas diferentes regiões produtoras de arroz (Andres et al., 2007).
O quinclorac destaca-se como um dos herbicidas mais utilizados na cultura do arroz, sendo classificado como mimetizador de auxina. Esse herbicida reúne várias das características consideradas favoráveis ao seu uso, como flexibilidade na aplicação (pré e pósemergência), eficácia no controle de espécies problemáticas como Echinochloa crusgalli e Aeschynomene rudis, baixa toxicidade ao homem e aos animais e seletividade à cultura do arroz (Andres et al., 2007). O herbicida quinclorac começou a ser usado nas lavouras de arroz do Sul do Brasil nos meados da década de 1990, porém seu uso foi limitado no final desta década, em razão das falhas relatadas pelos orizicultores no controle de capim-arroz. Nesse sentido, pesquisas começaram a ser feitas por várias instituições com o objetivo de confirmar a ocorrência ou não de resistência das plantas de capim-arroz a esse herbicida (Schuch et al., 2008; Concenço et al., 2009; Tironi et al., 2009).

Acredita-se que, se o biótipo de capim-arroz resistente a herbicida for mais competitivo que o suscetivel, provavelmente com o tempo possa ocorrer incremento em sua frequência na população, mesmo na ausência do agente selecionador. Por outro lado, se o biótipo resistente apresentar-se com menor potencial competitivo que o suscetivel, provavelmente sua frequência na maioria dos campos de arroz pode ser reduzida. Esse herbicida poderia, então, voltar a ser utilizado em um sistema de rotação de mecanismos de ação, como forma de retardar o surgimento de biótipos de capimarroz resistentes aos herbicidas. Em trabalho realizado por Ferreira et al. (2008), comprovouse que biótipos de azevém (Lolium multiflorum) resistentes ao glyphosate apresentaram menor potencial competitivo que o suscetivel e tendem a desaparecer na ausência do agente selecionador - neste caso, o herbicida glyphosate.

A competição entre plantas daninhas e culturas pode afetar quantitativa e qualitativamente a produção destas, pois modifica a eficiência de aproveitamento dos recursos disponiveis no ambiente, como água, luz e nutrientes (Sinclair et al., 1975; Melo et al., 2006). Essa competição ocorre também entre indivíduos de uma mesma espécie ou entre biótipos predominantes na área, conforme constatado por Ferreira et al. (2008), os quais verificaram que biótipos de azevém 
resistentes ao glyphosate possuem menor capacidade competitiva do que os suscetiveis.

Objetivou-se com este trabalho avaliar a competição entre biótipos de capim-arroz resistente e suscetivel ao quinclorac e plantas de arroz irrigadas.

\section{MATERIAL E MÉTODOS}

O experimento foi instalado em casa de vegetação com irrigação por nebulização, em delineamento experimental de blocos casualizados, em esquema fatorial $2 \times 6$ com quatro repetições. As unidades experimentais constaram de vasos de $13 \mathrm{~L}$ de substrato (mistura pré-elaborada de solo e terra vegetal, corrigida e adubada de acordo com análise de solo). Os tratamentos constaram de plantas dos biótipos de capim-arroz resistente e suscetível ao herbicida quinclorac, que competiram com uma planta de arroz da variedade BRS-Pelota. No centro da unidade experimental foram semeadas três sementes de arroz, enquanto na periferia da unidade experimental foram semeadas dez sementes de capim-arroz do biótipo resistente $(R)$ ou suscetível $(\mathrm{S})$ ao quinclorac, de acordo com os tratamentos propostos. As plântulas de arroz e de capimarroz foram desbastadas aos dez dias após a emergência (DAE), mantendo-se somente um indivíduo da cultura, e para a planta daninha deixou-se o número de plantas conforme os tratamentos propostos por unidade experimental.

Os tratamentos consistiram em manter uma planta de arroz no centro da unidade experimental, variando na periferia as densidades de capim-arroz em 0, 1, 2, 3, 4 ou 5 plantas do biótipo R ou S. A área de semeadura do biótipo central da unidade experimental foi delimitada por um círculo de $5 \mathrm{~cm}$ de diâmetro por $2 \mathrm{~cm}$ de profundidade, que possibilitou a identificação da planta central adulta, juntamente com os respectivos perfilhos, sem interferir na competição do biótipo central com as demais plantas da periferia, tanto na parte aérea como no sistema de raízes.

As unidades experimentais foram mantidas equidistantes, de forma que a área de superficie disponivel para o desenvolvimento das plantas correspondesse à área da unidade experimental. As plantas desenvolveram-se por $50 \mathrm{DAE}$, quando então foram seccionadas rente ao solo para aferição das massas fresca e seca e do conteúdo de água de folhas, colmos e toda a parte aérea. As folhas e colmos das plantas foram acondicionados separadamente em sacos plásticos contendo algodão embebido em água, acondicionados em caixa de isopor, sendo, depois disso, imediatamente transportados para o laboratório para aferição da massa fresca de folhas e colmos das plantas de arroz, que competiam com os biótipos de capim-arroz. Posteriormente, foram transferidos para sacos de papel e colocados para secar em estufa com circulação forçada de ar a $65^{\circ} \mathrm{C}$ até massa constante, quando então foi determinada a massa seca de folhas, colmos e total. O conteúdo de água de folhas e colmos foi calculado usando-se a fórmula (100*(MF - MS)/MF), sendo $\mathrm{MF}=$ massa fresca e MS = massa seca das plantas de arroz.

Todos os dados obtidos foram submetidos à análise de variância pelo teste $\mathrm{F}$; quando significativos, aplicou-se o teste de Duncan para comparação das médias entre densidades de plantas e o teste da Diferença Mínima Significativa (DMS) para avaliar diferenças entre o biótipo resistente e o suscetivel em cada tratamento (Pimentel-Gomes, 1990). Todos os dados foram analisados a $5 \%$ de probabilidade.

\section{RESULTADOS E DISCUSSÃO}

Observou-se que a produção de massa fresca de folhas (MFF) das plantas de arroz decresceu à medida que a densidade de plantas de capim-arroz $\mathrm{R} \mathrm{e} \mathrm{S}$ aumentou de zero até cinco plantas por unidade experimental (Tabela 1). De modo geral, até duas plantas de capim-arroz (suscetivel ou resistente ao quinclorac), competindo com a cultura, não provocou alteração na MFF da planta de arroz. No entanto, a partir de três plantas de capimarroz competindo com a cultura, a MFF da planta de arroz foi reduzida à medida que a densidade de capim-arroz foi aumentada para os dois biótipos em estudo. Quando a planta de arroz competiu com uma planta de capim-arroz resistente, não foram observadas diferenças na $\mathrm{MFF}$ em relação à testemunha livre de competição. Por sua vez, quando a planta de arroz competia com duas a cinco plantas de capim-arroz resistente, o acúmulo de MFF foi 
similar e inferior ao da testemunha, respectivamente.

Ao competir com as plantas de capim-arroz do biótipo suscetível, observaram-se diferenças marcantes na agressividade destas com a planta de arroz a partir da proporção 1:(1) do competidor até 1:(5); a proporção 1:(1) diferiu de todas as demais, com maior produção da MFF (Tabela 1). Plantas de arroz que competiam com as de capim-arroz do biótipo resistente possibilitaram a estratificação em dois níveis quanto ao acúmulo de MFF, enquanto o biótipo suscetivel ao herbicida quinclorac permitiu a disposição em três níveis. Não foram observadas diferenças quanto ao acúmulo de $\mathrm{MFF}$ em plantas de arroz, em função da competição com o biótipo resistente ou com o suscetível de capim-arroz, em todos os niveis de competição.

A massa fresca de colmos (MFC) das plantas de arroz foi alterada negativamente em função do aumento no número de plantas de capim-arroz competindo com a cultura, tanto do biótipo resistente como do suscetível ao quinclorac (Tabela 2). O biótipo de capim-arroz resistente apresentou comportamento similar ao relatado para MFF, ou seja, a partir da densidade 1:(2) não ocorreu mais diferenciação entre as MFC. Contudo, para o biótipo suscetível ocorreram diferenças de acordo com o

Tabela 1 - Massa fresca de folhas (MFF) de plantas de arroz irrigado, cv. BRS Pelota, em função da competição com plantas de capim-arroz dos biótipos resistente ou suscetível ao quinclorac

\begin{tabular}{|c|c|c|c|c|}
\hline \multicolumn{2}{|c|}{ Planta em competição } & Resistente $^{\mathrm{I}^{/}}$ & Suscetível $^{1 /}$ & Diferença $^{2}{ }^{-\prime}$ \\
\hline Arroz & Capim & \multicolumn{3}{|c|}{ MFF (g por planta ) } \\
\hline 1 & 0 & $1,55 \mathrm{a}^{\frac{3}{}}$ & $1,73 \mathrm{~b}$ & $-0,18 \mathrm{~ns}$ \\
\hline 1 & 1 & $1,45 \mathrm{a}$ & $2,28 \mathrm{a}$ & $-0,83 \mathrm{~ns}$ \\
\hline 1 & 2 & $0,49 \mathrm{~b}$ & $1,31 \mathrm{bc}$ & $-0,83 \mathrm{~ns}$ \\
\hline 1 & 3 & $0,60 \mathrm{~b}$ & $0,52 \mathrm{c}$ & $+0,08 \mathrm{~ns}$ \\
\hline 1 & 4 & $0,40 \mathrm{~b}$ & $0,52 \mathrm{c}$ & $-0,12 \mathrm{~ns}$ \\
\hline 1 & 5 & $0,37 \mathrm{~b}$ & $0,33 \mathrm{c}$ & $+0,04 \mathrm{~ns}$ \\
\hline
\end{tabular}

1/ Refere-se ao biótipo de capim-arroz com o qual a planta de arroz irrigado avaliada competia. 느 ns - não significativo; *,** significativo a 5 e $1 \%$ de probabilidade pelo teste da DMS, respectivamente. ${ }^{3 /}$ Médias seguidas da mesma letra, na coluna, não diferem entre si pelo teste de Duncan a $5 \%$ de probabilidade. aumento da densidade do competidor a partir de duas plantas e mantendo-se até a quinta, ressaltando ainda que o incremento da população de capim-arroz causou aumento considerável nas perdas de MFC do arroz. Do mesmo modo que o observado na variável MFF, para a MFC também se observou que a competição do arroz com capim-arroz resistente permitiu a estratificação em dois niveis quanto ao acúmulo de MFC, e com o biótipo suscetivel, em quatro niveis. De todas as proporções estudadas entre os biótipos de capim-arroz, observou-se haver diferenças quando a cultura do arroz competiu com uma planta de capimarroz tanto para o biótipo suscetível quanto para o resistente; nas demais proporções, a diferença não foi constatada.

A produção de massa fresca total da parte aérea da cultura (MFT) decresceu com o acréscimo no número de plantas de capimarroz do biótipo resistente e suscetível ao quinclorac (Tabela 3). No entanto, não se obteve diferença quando uma planta de arroz esteve na presença de uma planta de capimarroz para o biótipo resistente, sendo igual ao tratamento testemunha. Entretanto, o biótipo suscetivel ao quinclorac, de modo geral, produziu menor MFT em todas as proporções testadas, e valores menores ocorreram quando a população do capim-arroz foi mais elevada.

Tabela 2 - Massa fresca de colmos (MFC) de plantas de arroz irrigado, cv. BRS Pelota, em função da competição com plantas de capim-arroz dos biótipos resistente ou suscetível ao quinclorac

\begin{tabular}{|c|c|c|c|c|}
\hline \multicolumn{2}{|c|}{ Planta em competição } & Resistente $^{\mathrm{1} /}$ & Suscetível $^{1 /}$ & Diferença $^{2}{ }^{-}$ \\
\hline Arroz & Capim & \multicolumn{3}{|c|}{ MFC (g por planta) } \\
\hline 1 & 0 & $2,18 \mathrm{a}^{\frac{3}{}}$ & $3,17 \mathrm{a}$ & $-0,99 \mathrm{~ns}$ \\
\hline 1 & 1 & $2,19 \mathrm{a}$ & $3,54 \mathrm{a}$ & $-1,35 *$ \\
\hline 1 & 2 & $0,68 \mathrm{~b}$ & $1,38 \mathrm{~b}$ & $-0,70 \mathrm{~ns}$ \\
\hline 1 & 3 & $0,83 \mathrm{~b}$ & $0,85 \mathrm{c}$ & $-0,02 \mathrm{~ns}$ \\
\hline 1 & 4 & $0,61 \mathrm{~b}$ & $0,68 \mathrm{c}$ & $-0,08 \mathrm{~ns}$ \\
\hline 1 & 5 & $0,54 \mathrm{~b}$ & $0,36 \mathrm{~d}$ & $+0,18 \mathrm{~ns}$ \\
\hline
\end{tabular}

${ }^{1 /}$ Refere-se ao biótipo de capim-arroz com o qual a planta de arroz irrigado avaliada competia. ㄴ/ ns - não significativo; *,** significativo a 5 e $1 \%$ de probabilidade pelo teste da DMS, respectivamente. ${ }^{3 /}$ Médias seguidas da mesma letra, na coluna, não diferem entre si pelo teste de Duncan a $5 \%$ de probabilidade. 
Tabela 3 - Massa fresca total da parte aérea (MFT) de plantas de arroz irrigado, cv. BRS Pelota, em função da competição com plantas de capim-arroz dos biótipos resistente ou suscetível ao quinclorac

\begin{tabular}{|c|c|c|c|c|}
\hline \multicolumn{2}{|c|}{ Planta em competição } & Resistente $^{1 /}$ & Suscetível $^{1 /}$ & Diferença $^{2}$ \\
\hline Arroz & Capim & \multicolumn{3}{|c|}{ MFT (g por planta) } \\
\hline 1 & 0 & $3,73 \mathrm{a}^{3 /}$ & $4,90 \mathrm{~b}$ & $-1,17 \mathrm{~ns}$ \\
\hline 1 & 1 & $3,64 \mathrm{a}$ & $5,82 \mathrm{a}$ & $-2,18 *$ \\
\hline 1 & 2 & $1,17 \mathrm{~b}$ & $3,09 \mathrm{c}$ & $-1,92 *$ \\
\hline 1 & 3 & $1,43 \mathrm{~b}$ & $1,37 \mathrm{~d}$ & $+0,06 \mathrm{~ns}$ \\
\hline 1 & 4 & $1,00 \mathrm{~b}$ & $1,20 \mathrm{~d}$ & $-0,20 \mathrm{~ns}$ \\
\hline 1 & 5 & $0,91 \mathrm{~b}$ & $0,69 \mathrm{e}$ & $+0,22 \mathrm{~ns}$ \\
\hline
\end{tabular}

1/ Refere-se ao biótipo de capim-arroz com o qual a planta de arroz irrigado avaliada competia. ㄴ/ ns - não significativo; *,** significativo a 5 e $1 \%$ de probabilidade pelo teste da DMS, respectivamente. ${ }^{3 /}$ Médias seguidas da mesma letra, na coluna, não diferem entre si pelo teste de Duncan a $5 \%$ de probabilidade.

Ocorreu diferenciação em dois e cinco patamares dos biótipos de capim-arroz resistente e suscetivel, respectivamente, ao competirem com a cultura. Houve ainda diferenças entre os biótipos de capim-arroz resistente e suscetível competindo com o arroz na proporção de duas e três plantas.

A massa seca de folhas de arroz (MSF) decresceu com o aumento da densidade e de plantas dos biótipos de capim-arroz resistente e suscetivel ao herbicida, com exceção para a testemunha livre de competição e quando o arroz competia com uma planta de capim-arroz (Tabela 4). Entre duas e cinco plantas de capim-arroz competindo com uma de arroz, os resultados foram semelhantes para ambos os biótipos de capim-arroz, com exceção do suscetível na proporção de duas plantas, em relação a uma planta de arroz. Ressalta-se que os dois biótipos de capim-arroz competiram semelhantemente pelos recursos do meio com a cultura do arroz. Também, salienta-se que o biótipo de capim-arroz suscetivel apresentou a MSF, na média de todas as proporções testadas, $23 \%$ superior à do resistente.

Houve queda na produtividade de massa seca de colmos (MSC) quando a cultura esteve na presença dos biótipos resistente e suscetível, em função do aumento no número de
Tabela 4 - Massa seca de folhas (MSF) de plantas de arroz irrigado, cv. BRS Pelota, em função da competição com plantas de capim-arroz dos biótipos resistente ou suscetível ao quinclorac

\begin{tabular}{|c|c|c|c|c|}
\hline \multicolumn{2}{|c|}{ Planta em competição } & Resistente $^{1 /}$ & Suscetível $^{1 /}$ & Diferença $^{2}{ }^{\frac{}{}}$ \\
\hline Arroz & Capim & \multicolumn{3}{|c|}{ MSF (g por planta) } \\
\hline 1 & 0 & $0,40 \mathrm{a}^{\frac{3}{}}$ & $0,56 \mathrm{a}$ & $-0,16 \mathrm{~ns}$ \\
\hline 1 & 1 & $0,42 \mathrm{a}$ & $0,50 \mathrm{a}$ & $-0,08 \mathrm{~ns}$ \\
\hline 1 & 2 & $0,15 \mathrm{~b}$ & $0,35 \mathrm{~b}$ & $-0,20 \mathrm{~ns}$ \\
\hline 1 & 3 & $0,16 \mathrm{~b}$ & $0,16 \mathrm{c}$ & $-0,01 \mathrm{~ns}$ \\
\hline 1 & 4 & $0,13 \mathrm{~b}$ & $0,14 \mathrm{c}$ & $-0,02 \mathrm{~ns}$ \\
\hline 1 & 5 & $0,10 \mathrm{~b}$ & $0,09 \mathrm{c}$ & $+0,02 \mathrm{~ns}$ \\
\hline
\end{tabular}

1/ Refere-se ao biótipo de capim-arroz com o qual a planta de arroz irrigado avaliada competia. ${ }^{2} / \mathrm{ns}$ - não significativo; $*, * *$ significativo a 5 e $1 \%$ de probabilidade pelo teste da DMS, respectivamente. ${ }^{3 /}$ Médias seguidas da mesma letra, na coluna, não diferem entre si pelo teste de Duncan a $5 \%$ de probabilidade.

plantas, observando-se, ainda, diferenciação em três níveis quando o arroz competia com o biótipo resistente e em quatro competindo com o suscetivel (Tabela 5). No entanto, para o biótipo resistente ocorreu maior diferenciação entre a ausência de plantas competindo com a cultura até a proporção 1:(2), ou seja, uma planta de arroz competindo com duas de capimarroz. Com relação ao biótipo suscetível, observou-se a mesma tendência do resistente, com maior produção de MSC em todas as proporções de plantas. Observou-se, ainda, que houve diferença na competição do capim-arroz resistente e suscetivel com a cultura nas proporções $1:(1)$ e $1:(2)$ de capim-arroz, sendo o suscetivel mais competitivo que o resistente nas mesmas proporções.

A massa seca total da parte aérea (MST) das plantas de arroz foi alterada em função da intensidade de competição dos biótipos de capim-arroz resistente e suscetivel ao herbicida quinclorac (Tabela 6). Quando competindo com o biótipo resistente, somente a menor intensidade de competição não diferiu da testemunha livre de infestação. Em patamar inferior localizaram-se as densidades de duas a cinco plantas de capim-arroz, sendo estas iguais entre si. Quando as plantas de arroz competiram com as de capim-arroz do biótipo suscetivel, o comportamento foi similar ao da 
competição com as plantas do biótipo resistente, sendo possivel a estratificação em três niveis, enquanto a do resistente foi separada em dois niveis. Entretanto, diferenças quanto à testemunha não infestada foram observadas a partir da proporção 1:(2).

O conteúdo de água normalmente é utilizado como um dos indicadores mais sensiveis de que a planta está sob a influência de algum

Tabela 5 - Massa seca de colmos (MSC) de plantas de arroz irrigado, cv. BRS Pelota, em função da competição com plantas de capim-arroz dos biótipos resistente ou suscetível ao quinclorac

\begin{tabular}{|c|c|c|c|c|}
\hline \multicolumn{2}{|c|}{ Planta em competição } & Resistente $^{{ }^{1 /}}$ & Suscetível $^{{ }^{1 /}}$ & Diferença $^{2}{ }^{2}$ \\
\hline Arroz & Capim & \multicolumn{3}{|c|}{ MSC (g por planta) } \\
\hline 1 & 0 & $0,29 \mathrm{~b}^{3 /}$ & $0,33 \mathrm{~b}$ & $-0,04 \mathrm{~ns}$ \\
\hline 1 & 1 & $0,37 \mathrm{a}$ & $0,58 \mathrm{a}$ & $-0,31 *$ \\
\hline 1 & 2 & $0,10 \mathrm{c}$ & $0,27 \mathrm{c}$ & $-0,18^{*}$ \\
\hline 1 & 3 & $0,12 \mathrm{c}$ & $0,14 \mathrm{~d}$ & $-0,02 \mathrm{~ns}$ \\
\hline 1 & 4 & $0,10 \mathrm{c}$ & $0,11 \mathrm{~d}$ & $-0,01 \mathrm{~ns}$ \\
\hline 1 & 5 & $0,07 \mathrm{c}$ & $0,08 \mathrm{~d}$ & $-0,01 \mathrm{~ns}$ \\
\hline
\end{tabular}

1/ Refere-se ao biótipo de capim-arroz com o qual a planta de arroz irrigado avaliada competia. ${ }^{2} / \mathrm{ns}$ - não significativo; *,** significativo a 5 e $1 \%$ de probabilidade pelo teste da DMS, respectivamente. ${ }^{3 /}$ Médias seguidas da mesma letra, na coluna, não diferem entre si pelo teste de Duncan a $5 \%$ de probabilidade.

Tabela 6 - Massa seca total de parte aérea (MST) de plantas de arroz irrigado, cv. BRS Pelota, em função da competição com plantas de capim-arroz dos biótipos resistente ou suscetível ao quinclorac

\begin{tabular}{|c|c|c|c|c|}
\hline \multicolumn{2}{|c|}{ Planta em competição } & Resistente $^{1 /}$ & Suscetível $^{\frac{1}{}}$ & Diferença $^{2}{ }^{2}$ \\
\hline Arroz & Capim & \multicolumn{3}{|c|}{ MST (g por planta) } \\
\hline 1 & 0 & $0,69 \mathrm{a}^{3 /}$ & $0,89 \mathrm{a}$ & $-0,20 \mathrm{~ns}$ \\
\hline 1 & 1 & $0,79 \mathrm{a}$ & $1,08 \mathrm{a}$ & $-0,29 \mathrm{~ns}$ \\
\hline 1 & 2 & $0,25 \mathrm{~b}$ & $0,62 \mathrm{~b}$ & $-0,38 \mathrm{~ns}$ \\
\hline 1 & 3 & $0,27 \mathrm{~b}$ & $0,30 \mathrm{bc}$ & $-0,03 \mathrm{~ns}$ \\
\hline 1 & 4 & $0,22 \mathrm{~b}$ & $0,25 \mathrm{bc}$ & $-0,03 \mathrm{~ns}$ \\
\hline 1 & 5 & $0,17 \mathrm{~b}$ & $0,16 \mathrm{c}$ & $+0,01 \mathrm{~ns}$ \\
\hline
\end{tabular}

1/ Refere-se ao biótipo de capim-arroz com o qual a planta de arroz irrigado avaliada competia. ${ }^{2 /} \mathrm{ns}$ - não significativo; $*, * *$ significativo a 5 e $1 \%$ de probabilidade pelo teste da DMS, respectivamente. ${ }^{3 /}$ Médias seguidas da mesma letra, na coluna, não diferem entre si pelo teste de Duncan a $5 \%$ de probabilidade. agente causador de estresse (Wort, 1964). Normalmente, sob altas ou baixas temperaturas, tratamento herbicida ou sombreamento, o conteúdo de água tende a ser alterado antes mesmo que diferenças possam ser encontradas na massa fresca ou seca, das quais deriva. Além disso, aumentos consideráveis no conteúdo de água podem ser observados quando as plantas estão sob alta competição por luz, uma vez que a pressão de turgescência é a responsável pelo alongamento celular e consequente alongamento da parte aérea das plantas (Vysotskaya et al., 2003). Quanto ao conteúdo de água nas folhas (CAF) e nos colmos (CAC) nas plantas de arroz cultivar BRS Pelota, observou-se neste trabalho que não houve diferença na competição de plantas de arroz com plantas de um ou de outro biótipo de capim-arroz, quando sob mesma intensidade de competição. Quando não se constatam diferenças entre espécies ou biótipos que competem entre si, significa que não há efeito de um sobre outro, ou que a habilidade competitiva dessas plantas em interferir uma sobre a outra se equivale, ou ainda que as plantas possuem habilidades competitivas basicamente semelhantes para a variável em estudo (Radosevich et al., 1997; Agostinetto et al., 2008). De modo geral, para todas as variáveis avaliadas, observou-se efeito aditivo ou sinérgico onde o valor da variável em estudo aumentou na proporção 1:(1), quando as plantas de arroz estavam sob baixa intensidade competitiva com plantas de capimarroz. Em outras palavras, sob baixa intensidade de competição por determinado recurso, as plantas tendem a estimular certos processos fisiológicos, de forma a serem superiores às plantas com as quais competem. Nas demais proporções geralmente houve decréscimo da produtividade de MFF, MFC, MFT, MSF, MSC, MST e conteúdo de água em folhas e colmos (Tabelas 1, 2, 3, 4, 5, 6, 7 e 8). De acordo com Casper \& Jackson (1997), as vantagens da plasticidade, ou capacidade de competição de uma planta, podem ser vistas em termos de quanto recurso adicional será capturado e quão rapidamente irá ocorrer sua adição. Esse comportamento demonstra que determinada espécie pode ser mais competitiva que outra em determinadas condições, mas que em outras podem equivaler-se e, assim, contribuir mais que o esperado para a produtividade total 
(Radosevich, 1997; Fleck et al., 2008; Agostinetto et al., 2008).

O capim-arroz, por possuir o metabolismo $\mathrm{C}_{4}$, é altamente competitivo durante o verão, tendo elevada capacidade de extração de recursos naturais do ambiente para realizar processos essenciais, como a fotossintese (Taiz $\&$ Zeiger, 2004; Silva et al., 2007). Pelo fato de o arroz ser planta $C_{3}$ cultivada no verão, o

Tabela 7 - Conteúdo de água em folhas (CAF) de plantas de arroz irrigado, cv. BRS Pelota, em função da competição com plantas de capim-arroz dos biótipos resistente ou suscetível ao quinclorac

\begin{tabular}{|c|c|c|c|c|}
\hline \multicolumn{2}{|c|}{ Planta em competição } & Resistente $^{1 /}$ & Suscetível $^{1 /}$ & Diferença $^{2}{ }^{2}$ \\
\hline Arroz & Capim & \multicolumn{3}{|c|}{ CAF (\%) } \\
\hline 1 & 0 & $69,8 \mathrm{a}^{\frac{3}{}}$ & $66,9 \mathrm{a}$ & $+2,88$ \\
\hline 1 & 1 & $66,6 \mathrm{a}$ & $70,1 \mathrm{a}$ & $-3,50$ \\
\hline 1 & 2 & $69,2 \mathrm{a}$ & $69,7 \mathrm{a}$ & $-0,55$ \\
\hline 1 & 3 & $72,7 \mathrm{a}$ & $69,3 \mathrm{a}$ & $+3,36$ \\
\hline 1 & 4 & $68,4 \mathrm{a}$ & $72,9 \mathrm{a}$ & $-4,48$ \\
\hline 1 & 5 & $72,9 \mathrm{a}$ & $71,6 \mathrm{a}$ & $+1,26$ \\
\hline
\end{tabular}

1/ Refere-se ao biótipo de capim-arroz com o qual a planta de arroz irrigado avaliada competia. $\stackrel{2}{2} \mathrm{~ns}$ - não significativo; *,** significativo a 5 e $1 \%$ de probabilidade pelo teste da DMS, respectivamente. ${ }^{3 /}$ Médias seguidas da mesma letra, na coluna, não diferem entre si pelo teste de Duncan a $5 \%$ de probabilidade.

Tabela 8 - Conteúdo de água em colmos (CAC) de plantas de arroz irrigado, cv. BRS Pelota, em função da competição com plantas de capim-arroz dos biótipos resistente ou suscetível ao quinclorac

\begin{tabular}{|c|c|c|c|c|}
\hline \multicolumn{2}{|c|}{ Planta em competição } & Resistente $^{1 /}$ & Suscetível $^{1 /}$ & Diferença $^{2}{ }^{-1}$ \\
\hline Arroz & Capim & \multicolumn{3}{|c|}{ CAC (\%) } \\
\hline 1 & 0 & $86,2 \mathrm{a}^{\frac{3}{}}$ & $85,8 \mathrm{a}$ & $+0,37 \mathrm{~ns}$ \\
\hline 1 & 1 & $81,4 \mathrm{a}$ & $86,5 \mathrm{a}$ & $-5,15 \mathrm{~ns}$ \\
\hline 1 & 2 & $85,1 \mathrm{a}$ & $84,5 \mathrm{a}$ & $+0,56 \mathrm{~ns}$ \\
\hline 1 & 3 & $86,2 \mathrm{a}$ & $84,3 \mathrm{a}$ & $+1,81 \mathrm{~ns}$ \\
\hline 1 & 4 & $83,1 \mathrm{a}$ & $83,5 \mathrm{a}$ & $-0,35 \mathrm{~ns}$ \\
\hline 1 & 5 & $86,5 \mathrm{a}$ & $79,1 \mathrm{a}$ & $+7,41 *$ \\
\hline
\end{tabular}

1/ Refere-se ao biótipo de capim-arroz com o qual a planta de arroz irrigado avaliada competia. ${ }^{2 /} \mathrm{ns}$ - não significativo; *,** significativo a 5 e $1 \%$ de probabilidade pelo teste da DMS, respectivamente. ${ }^{3 /}$ Médias seguidas da mesma letra, na coluna, não diferem entre si pelo teste de Duncan a $5 \%$ de probabilidade. capim-arroz é normalmente beneficiado pelo ambiente em termos competitivos.

Observa-se também que em situações de estresse as plantas de arroz podem apresentar baixa capacidade competitiva com as plantas daninhas, evidenciando assim necessidade da realização de controle e da observância do período crítico de competição na cultura (Silva $\&$ Durigan, 2006). Nesse sentido, Balbinot Jr. et al. (2003) ressaltam que a habilidade de plantas em sombrear o solo é uma das variáveis que mais se relacionam com o potencial competitivo e que essa característica também está associada ao acúmulo de massa aérea pelas plantas da cultura do arroz.

Outros estudos avaliaram também a capacidade competitiva de diferentes biótipos de plantas da mesma espécie. Por exemplo, Agostinetto et al. (2004) concluíram que plantas infestantes de arroz-daninho são mais competitivas que plantas de arroz melhoradas por vários recursos do ambiente e que isso decorre de inúmeros fatores, como época de emergência das plantas, tipo de cultivar semeado, adubação nitrogenada, densidade de semeadura e espaçamento entre linhas, entre outros. Também avaliando a competição de cultivares de arroz com o capim-arroz, Galon et al. (2007a, b) observaram que, à medida que população, massa seca aérea, cobertura do solo e área foliar da planta daninha aumentam, ocorre redução brusca na produtividade de grãos do arroz, podendo chegar até mesmo a $100 \%$ em altas infestações quando nenhum controle for efetuado.

Os resultados obtidos neste trabalho permitem inferir que provavelmente as plantas se encontravam em adequado status metabólico e que o comportamento quanto ao incremento na altura e à menor produção de outras variáveis, como a massa fresca de plantas, provavelmente é resultado da competição, sem maiores danos ao metabolismo da planta (Tobe et al., 2005). O menor conteúdo de água na planta provoca menor alongamento celular em seus órgãos.

Normalmente observa-se que em gramineas o número de folhas por perfilho é aproximadamente constante (Wang et al., 2005). No entanto, a dimensão desses órgãos é altamente influenciada por fatores do 
ambiente, estreitamente relacionados à imposição de competição. A altura normalmente está mais associada à necessidade de luz, podendo ou não ter relação com as demais variáveis analisadas, principalmente em função da densidade de plantas, do metabolismo e da disponibilidade de luz (Radosevich et al., 1997). Pode-se inferir ainda que a área foliar específica (SLA) que atua preponderantemente na relação entre massa e área foliar, e simplificadamente define a espessura da folha; ela pode ser alterada por fatores como temperatura, intensidade de luz, balanço de nutrientes no solo e aplicação de agroquímicos (Wang et al., 2005), podendo ainda ser dependente do próprio biótipo.

Deve-se salientar que a proximidade genética entre as plantas pode induzir alterações na morfologia e na alocação de assimilados (Ballaré et al., 1995), e isso pode ser um dos motivos da modificação de acumulação de massa seca entre os diferentes órgãos, como demonstrado por Wobeto (1994), ao comparar o sincronismo nas taxas de acumulação entre diferentes órgãos das plantas de cevada competindo entre si em nivel de lavoura. Nesse mesmo sentido, Davis \& Simmons (1994) relataram que as plantas apresentam capacidade de detectar e responder morfologicamente à alteração da qualidade ou da quantidade de elementos considerados essenciais ao seu desenvolvimento, como água, luz, nutrientes e espaço.

Alguns trabalhos relatam que a acumulação de fotoassimilados pelas plantas em diferentes órgãos, sejam aéreos ou subterrâneos, como folhas, caules e raizes, depende da capacidade que elas apresentam para capturálos no ambiente e também da ocorrência de estresses bióticos ou abióticos, destacando-se como um dos principais em condições de lavoura a competição pelos elementos essenciais, principalmente em plantas com características morfofisiológicas semelhantes (Wobeto, 1994; Ballaré et al., 1995). Nesse sentido, foi observado nesta pesquisa que o cultivar de arroz BRS Pelota, ao competir com os biótipos de capim-arroz resistentes e suscetiveis ao herbicida quinclorac, exibiu decréscimo na produtividade das variáveis estudadas e, consequentemente, na deposição de fotoassimilados em diferentes órgãos das plantas de arroz em função da intensa interferência dos biótipos de capim-arroz.

De maneira geral, observa-se que plantas de arroz foram afetadas pelo aumento no número de plantas de capim-arroz competindo com a cultura, mas não foram observadas diferenças na maioria das variáveis estudadas em função dos biótipos com os quais essas plantas competiam. Em condições de lavoura, pode-se inferir que, provavelmente, o momento considerado ideal para controle das plantas de capim-arroz, tanto dos biótipos resistentes como dos suscetiveis, deve ser realizado quando se atingir uma população que possa vir a causar danos econômicos à cultura do arroz, sendo ela independente do biótipo presente na lavoura.

\section{AGRADECIMENTOS}

Ao Conselho Nacional de Desenvolvimento Científico e Tecnológico (CNPq), pela concessão de bolsas; e ao pesquisador da EPAGRI Itajaí-SC, na área de Plantas Daninhas, Ph.D. José Alberto Noldin, pelo envio de sementes de populações de biótipos de capim-arroz resistente e suscetivel ao herbicida quinclorac, oriundas de Itajaí-SC.

\section{LITERATURA CITADA}

AGOSTINETTO, D. et al. Competitividade relativa entre cultivares de arroz irrigado e biótipo de capim-arroz

(Echinochloa spp.). Planta Daninha, v. 26, n. 4, p. 757-766, 2008.

AGOSTINETTO, D. et al. Influência de cultivares de arroz e épocas da adubação nitrogenada nas relações de interferência da cultura com cultivar simulador de infestação de arroz-vermelho. Planta Daninha, v. 22, n. 2, p. 185-193, 2004.

ANDRES, A. et al. Detecção da resistência de capim-arroz (Echinochloa sp.) ao herbicida quinclorac em regiões orizícolas do sul do Brasil. Planta Daninha, v. 25, n. 1, p. 221-226, 2007.

BALBINOT JR., A. A. et al. Competitividade de cultivares de arroz irrigado com cultivar simuladora de arroz-vermelho. Pesq. Agropec. Bras., v. 38, n. 1, p. 53-59, 2003.

BALLARÉ, C. L.; SCOPEL, A. L.; SANCHEZ, R. A. Plant photomorphogenesis in canpopies, crop growth, and yield. Hortic. Sci., v. 30, n. 6, p. 1172-1181, 1995. 
CASPER, B. B.; JACKSON, R. B. Plant competition underground. Ann. Rev. Ecol. System., v. 28, p. 545-570, 1997.

CONCENÇO, G. Effect of dose and application site on quinclorac absorption by barnyardgrass biotypes. Planta Daninha, v. 27, n. 3, p. 541-548, 2009.

DAVIS, M. H.; SIMMONS, S. R. Far-red reflected from neighbouring vegetation promotes shoot elongation and accelerates flowering in spring barley plant. Plant Cell Environ., v. 17, n. 7, p. 829-836, 1994.

FERREIRA, E. A. et al. Potencial competitivo de biótipos de azevém (Lolium multiflorum). Planta Daninha, v. 26, n. 2, p. 261-269, 2008.

FLECK, N. G. et al. Interferência de plantas concorrentes em arroz irrigado modificada por métodos culturais. Planta Daninha, v. 22, n. 1, p. 19-28, 2004.

FLECK, N. G. et al. Competitividade relativa entre cultivares de arroz irrigado e biótipo de arroz-vermelho. Planta Daninha, v. 26, n. 1, p. 101-111, 2008.

GALON, L. et al. Estimativa das perdas de produtividade de grãos em cultivares de arroz (Oryza sativa) pela interferência do capim-arroz (Echinochloa spp.). Planta Daninha, v. 25, n. 4, p. $697-707,2007 \mathrm{a}$.

GALON, L. et al. Níveis de dano econômico para decisão de controle de capim-arroz (Echinochloa spp.) em arroz irrigado (Oryza sativa). Planta Daninha, v. 25, n. 4, p. 709-718, $2007 b$.

INSTITUTO RIO-GRANDENSE DO ARROZ - IRGA. Arroz irrigado no RS - área, produção e rendimento. Disponível em: $<$ http://www.irga.rs.gov.br $>$ Acesso em: 5 ago. 2007.

LÓPEZ-MARTINEZ, N.; MARSHALL, G.; DePRADO, R. Resistance of barnyardgrass (Echinochloa crus-galli) to atrazine and quinclorac. Pestic. Sci., v. 51, n. 2, p. 171-175, 1997.

MELO, P. T. B. S. et al. Comportamento de populações de arroz irrigado em função das proporções de plantas originadas de sementes de alta e baixa qualidade fisiológica. R. Bras. Agroc., v. 12, n. 1, p. 37-43, 2006.

PIMENTEL-GOMES, F. Curso de estatística experimental. Piracicaba: Nobel, 1990. 468 p.

RADOSEVICH, S.; HOLT, J.; GHERSA, C. Weed ecology: implications for management. 2.ed. New York: Wiley, 1997. $588 \mathrm{p}$.
RUIZ-SANTELLA, J. P.; FISCHER, A. J.; DePRADO, R. Alternative control of two biotypes of Echinochloa phyllopogon susceptible and resistant to fenoxaprop-ethyl.

Comm. Agric. Appl. Biol. Sci., v. 68, n. 4, p.403-407, 2003.

SCHUCH, L. O. B. et al. Crescimento de raízes de biótipos de capim-arroz resistente e suscetível ao quinclorac em competição. Planta Daninha, v. 26, n. 4, p. 893-900, 2008.

SILVA, M. R. M.; DURIGAN, J. C. Períodos de interferência das plantas daninhas na cultura do arroz de terras altas I Cultivar IAC 202. Planta Daninha, v. 24, n. 4, p. 685-694, 2006.

SILVA, A. A. et al. Competição entre plantas daninhas e culturas. In: SLVA, A. A.; SILVA, J. F. (Eds.) Tópicos em manejo de plantas daninhas. Viçosa, MG: Universidade Federal de Viçosa, 2007. p. 17-61.

SINCLAIR, T. R. et al. Water use efficiency of field-grown maize during moisture stress. Plant Physiol., v. 56, p. $245-249,1975$.

SOCIEDADE SUL-BRASILEIRA DE ARROZ IRRIGADO - SOSBAI. Arroz irrigado: Recomendações técnicas da pesquisa para o Sul do Brasil. Santa Maria: Universidade Federal de Santa Maria, 2005. 159 p.

TAIZ, L.; ZEIGER, E. Fisiologia vegetal. 3.ed. Porto Alegre: Artmed, 2004. 719 p.

TIRONI, S. P. et al. Habilidade competitiva de plantas de arroz com biótipos de capim-arroz resistente ou suscetível ao quinclorac. Planta Daninha, v. 27, n. 2, p. 257-263, 2009.

TOBE, K.; ZHANG, L.; OMASA, K. Seed germination and seedling emergence of three annuals growing on desert sand dunes in china. Ann. Bot., v. 95, n. 4, p. 649-659, 2005.

VYSOTSKAYA, L. B. et al. Effect of partial root excision on shoot water relations. J. Plant Physiol., v. 160, n. 9, p. $1011-1015,2003$.

WANG, L; SHOWALTER, A. M.; UNGAR, I. A. Effects of intraspecific competition on growth and photosynthesis of Atriplex prostrata. Aquatic Bot., v. 83, n. 3, p. 187-192, 2005.

WOBETO, C. Padrão de afilhamento, sobrevivência de afilhos e suas relações com o rendimento de grãos em trigo. 1994. 102 f. Dissertação (Mestrado em Fitotecnia) Universidade Federal do Rio Grande do Sul, Porto Alegre, 1994.

WORT, D. J. Responses of plants to subletal concentrations of 2,4-D, without and with added minerals. In: AUDUS, L. J. (Ed.). The physiology and biochemistry of herbicides. New York: Academic Press, 1964. p. 335-342. 